\title{
ToxR of Vibrio cholerae affects biofilm, rugosity and survival with Acanthamoeba castellanii
}

\author{
Soni P Valeru', Sun N Wai ${ }^{2}$, Amir Saeed ${ }^{1}$, Gunnar Sandström ${ }^{1}$ and Hadi Abd ${ }^{1 *}$
}

\begin{abstract}
Background: Vibrio cholerae causes the diarrheal disease cholera and utilizes different survival strategies in aquatic environments. $V$. cholerae can survive as free-living or in association with zooplankton and can build biofilm and rugose colonies. The bacterium expresses cholera toxin (CT) and toxin-coregulated pilus (TCP) as the main virulence factors. These factors are co-regulated by a transcriptional regulator ToxR, which modulates expression of outer membrane proteins $(\mathrm{OmpU})$ and $(\mathrm{OmpT})$. The aims of this study were to disclose the role of ToxR in expression of OmpU and OmpT, biofilm and rugose colony formation as well as in association with the free-living amoeba Acanthamoeba castellanii at different temperatures.
\end{abstract}

Results: The tox $R$ mutant $V$. cholerae produced OmpT, significant biofilm and rugose colonies compared to the wild type that produced $\mathrm{OmpU}$, decreased biofilm and did not form rugoes colonies at $30^{\circ} \mathrm{C}$. Interestingly, neither the wild type nor toxR mutant strain could form rugose colonies in association with the amoebae. However, during the association with the amoebae it was observed that $A$. castellanii enhanced survival of $V$. cholerae wild type compared to toxR mutant strain at $37^{\circ} \mathrm{C}$.

Conclusions: ToxR does seem to play some regulatory role in the OmpT/OmpU expression shift, the changes in biofilm, rugosity and survival with A. castellanii, suggesting a new role for this regulatory protein in the environments.

Keywords: V. cholerae, Outer membrane proteins, Rugose colonies, Biofilm, Association with amoebae

\section{Background}

Vibrio cholerae is a gram-negative bacterium causing severe diarrhoeal disease cholera in Asia, Africa, and America. Many millions of cholera cases occurred endemically and pandemically worldwide [1].

$V$. cholerae adopts several survival strategies in aquatic environments. The bacterium can survive as free-living or in association with phytoplankton/zooplankton, crustaceans, and molluscs in coastal and estuarine environments [2]. V. cholerae forms biofilms on biotic and abiotic surfaces, thereby protecting themselves with this exopolymer barrier [3], biofilm can provide protection from toxic compounds, such as antibiotics, thermal stress, and predation [4]. The bacterium has been described to switch between the smooth and rugose

\footnotetext{
* Correspondence: hadi.abd@ki.se

'Karolinska Institute, Department of Laboratory Medicine, Division of Clinical Microbiology, Karolinska University Hospital, Huddinge, SE-141 86, Stockholm, Sweden

Full list of author information is available at the end of the article
}

colony morphotypes contributing to its environmental survival. The exopolysaccharide (EPS) materials of rugose colony-forming $V$. cholerae strains were recognized as a heavy, fibrous, electron-dense, ferretin-stained layer surrounding the cells, but smooth colony $V$. cholerae did not appear to have this EPS layer surrounding it [5]. The cell surface EPS materials confer a rugose colony morphology and resistance to osmotic and oxidative stresses. The regulation of EPS synthesis in bacteria is complex and involves multiple systems utilizing both positive and negative regulation [5].

Recent studies have shown that $V$. cholerae has developed a new survival strategy to grow and survive inside free-living amoeba Acanthamoeba castellanii [6-10].

$V$. cholerae expresses cholera toxin and toxin-coregulated pilus as the main virulence factors, which are coregulated by a transcriptional regulator ToxR. ToxR, however, independently of the transcriptional activators TcpP and ToxT, modulates expression of two outer membrane proteins OmpU and OmpT. Transcription of

\section{() Biomed Central}


ompU is induced by Tox $\mathrm{R}$, whereas transcription of ompT is repressed by ToxR [11,12].

In this paper we study the effect of ToxR regulatory protein in expression of OmpU and OmpT, biofilm and rugosity as well as survival of $V$. cholerae $\mathrm{O} 1$ with $A$. castellanii by constructing a tox $R$ deletion mutant.

\section{Methods}

\section{Bacterial strains and plasmids used in this study}

The bacterial strains and plasmids used in this study are listed in Table 1. Strains were grown in LB medium at $37^{\circ} \mathrm{C}$. Strains were stored frozen in LB medium with $15 \%$ glycerol at $-80^{\circ} \mathrm{C}$. Antibiotics were used at the following concentrations: carbencillin $50 \mu \mathrm{g} / \mathrm{mL}$, streptomycin $50 \mu \mathrm{g} / \mathrm{ml}$, kanamycin $50 \mu \mathrm{g} / \mathrm{mL}$.

\section{Growth conditions}

Luria-Bertani (LB) media, All strains were grown in LB medium (1\% Bacto Tryptone, 0.5\% yeast extract, 0.5\% $\mathrm{NaCl}$ ) with appropriate selection. For antibiotic selection, $50 \mu \mathrm{g} / \mathrm{mL}$ carbenicillin or $50 \mu \mathrm{g} / \mathrm{mL}$ streptomycin was used.

\section{Construction of the internal in-frame toxR deletion mutant}

To introduce a deletion at the chromosomal toxR locus we used a double cross over procedure. A plasmid pCVD442 was used as a suicidal vector. In the first step two different asymmetric polymerase chain reactions (PCR) amplified with primers toxR-A (5'CCC ATC CAC TAA ACG GTA CCA TCC GAA CAT CTA ATG TCC CAG-3') toxR-B (5'-GCG TCT AGA ACT CTT TAC CTT CTT CAC GCAG-3') toxR-C (5'-GCG TCT AGA ATC TTC GCT GAA GGT ATG CAGT-3') and toxRD(5'TGG TAC CGT TTA GTG GAT GGG GCC ATC AAA GTG TGT GAG TAG-3') were used to generate fragments upstream and downstream of the sequences targeted for deletion. In the second step, the upstream and downstream fragments were annealed at their overlapping region and amplified by PCR as a single fragment, using the outer primers (toxR-A and toxR-D).
The PCR products were phenol-chloroform extracted, ethanol precipitated, washed with $70 \%$ ethanol, vacuum dried, resuspended in $50 \mathrm{~mL}$ of Xba-I restriction buffer containing $40 \mathrm{U}$ of $\mathrm{XbaI}$ restriction enzyme, and digested overnight at $37^{\circ} \mathrm{C}$. The DNA fragments were gel purified, ligated into $\mathrm{XbaI}$ digested and alkaline phosphatase-treated pCVD442 and then, electroporated into $E$. coli SM10גpir. The mutant constructs were checked by PCR and sequencing. The confirmed deletion constructs were introduced into $V$. cholerae by conjugation, screened on $15 \%$ sucrose containing plates, and the carbenicillin sensitive clones were assessed for double cross-over recombination. The recombinant colonies were checked by PCR.

\section{Expression of outer membrane proteins}

Bacterial cultures were grown overnight in $2 \mathrm{ml} \mathrm{LB}$ media at $37^{\circ} \mathrm{C}$. The entire contents were centrifuged at $18,000 \times \mathrm{g}$ for $15 \mathrm{~min}$. The supernatants were collected in new tubes and the pellet was suspended in $100 \mu \mathrm{l}$ sample buffer and boiled for $10 \mathrm{~min}$. The supernatant samples were precipitated with $10 \%$ TCA for $30 \mathrm{~min}$ on ice. The samples were centrifuged at $18,000 \times \mathrm{g}$ for 30 min and washed with $80 \%$ acetone. The pellet was resuspended in standard SDS-PAGE sample buffer. Samples were analysed by $13 \%$ SDS-PAGE.

\section{Biofilm analysis}

$V$. cholerae wild type and tox $R$ mutant strains were grown on $\mathrm{LB}$ agar plates overnight at $37^{\circ} \mathrm{C}$. Few colonies from each strain were suspended in $20 \mathrm{~mL} \mathrm{LB}$ broth and incubated in shaking incubator until the absorbance reached 0.6 units at $600 \mathrm{~nm} .5 \mathrm{~mL}$ of 1:100 dilution of this suspension was transferred into triplicated glass tubes $\left(13\right.$ by $100 \mathrm{~mm}$ ) and incubated for $18 \mathrm{~h}$ at $30^{\circ} \mathrm{C}$. Representative biofilm formed by wild type and tox $R$ mutant strains was visualised photographically and the tubes were rinsed with distilled water then filled with $1 \%$ crystal violet stain. After $15 \mathrm{~min}$, the tubes were rinsed and the biofilm-associated crystal violet in the tubes was suspended with $95 \%$ ethanol. The absorbance

Table 1 Bacterial strains and plasmids used in this study

\begin{tabular}{|c|c|c|}
\hline Strain or plasmid & Description & Reference \\
\hline V. cholerae O1 E1Tor Inaba & Strain A1552, Wild type & [13] \\
\hline V. cholerae $\triangle$ tox $R$ & Transcriptional activator deletion mutant of Strain A1552 & This study \\
\hline E. coli DH5 $\alpha$ & Ф80d/acZDM15 recAlgyrA96 thi-1 hsdR17 $\left(\mathrm{r}_{\mathrm{k}}^{-} \mathrm{m}_{\mathrm{k}}{ }^{+}\right)$supE44 & [14] \\
\hline \multirow[t]{3}{*}{ Sm10גpir } & relA1deoRA(lacZYA-argF)U169 & {$[15]$} \\
\hline & thi-1, thr, leu, tonA, lacY, supE, & \\
\hline & recA::Rp4-2-Tc::Mu,Km ${ }^{\mathrm{R}},(\lambda$ pir $)$ & \\
\hline Plasmid Puc 18 & $\mathrm{Ap}^{\mathrm{R}}$ lacZaovi colE1 & [16] \\
\hline Plasmid PCVD442 & oriR6K mobRP4 sacB Ap ${ }^{r}$ & this study \\
\hline
\end{tabular}


of the resulting suspension was measured by spectrophotometry at $570 \mathrm{~nm}$ to quantify the biofilm formation.

\section{Colony morphology}

For colony morphology assay, $V$. cholerae wild type and toxR mutant strains were grown on LB agar plates for 1 day at $30^{\circ} \mathrm{C}$ and left at room temperature until appearance of rugose colonies after 6 days. Percentage of rugose colonies was estimated and representative smooth as well as rugose colonies were visualized photographically.

\section{Co-cultivation assay}

The co-cultivation assay was based on a method presented previously. Axenically maintained amoebae were grown at $30^{\circ} \mathrm{C}$ to a final concentration of $2 \times 10^{5} \mathrm{CFU} /$ $\mathrm{mL}$ in ATCC medium as described above. Co-cultivations of $V$. cholerae with A. castellanii were incubated in NUNC tissue culture flasks $(75 \mathrm{~cm})$ purchased from VWR International (Stockholm, Sweden) filled with 50 mL ATCC medium 712 containing A. castellanii at a concentration of $2 \times 10^{5} \mathrm{CFU} / \mathrm{mL}$ and the particular $V$. cholerae species at a concentration of $2 \times 10^{6} \mathrm{CFU} / \mathrm{mL}$. Control flasks containing bacteria or amoebae only were prepared in the same way and with the same initial concentration as the co-culture flasks. All flasks were triplicates and incubated at $25^{\circ} \mathrm{C}$ and $37^{\circ} \mathrm{C}$. Samples were taken and plated on blood agar plates regularly to study growth and survival of $V$. cholerae.

\section{Results}

Construction of a $\Delta$ tox $R$ in $V$. cholerae and expression of outer membrane proteins

An internal in-frame toxR deletion mutant in $V$. cholerae was constructed as described in the materials and methods and examined for expression of outer membrane proteins by SDS-PAGE. The result showed that the $V$. cholerae tox $R$ mutant strain expressed OmpT compared to the wild type strain, which expressed OmpU (Figure 1)

\section{Biofilm analysis}

To study the effect of ToxR in biofilm formation at $30^{\circ} \mathrm{C}$ in LB broth, the biofilm and biofilm-associated crystal violet formed by the wild type $V$. cholerae or the tox $R$ mutant strains was visualised photographically and absorbance of the biofilm-associated crystal violet ethanol solution was measured spectrophotometrically.

The photographical analysis showed that the wild type $V$. cholerae (Figure 2A upper panel) had repressed biofilm formation compared to the toxR mutant strain (Figure $2 \mathrm{~B}$ upper panel). Moreover, it was found that the absorbance of the biofilm produced by the wild type $V$. cholerae (Figure 2A lower panel) and the toxR mutant strain (Figure 2B lower panel) were $1.1 \pm 0.2$ and $1.8 \pm$ 0.35 , respectively. However, the spectrophotometry showed that the toxR mutant of $V$. cholerae had enhanced biofilm formation, which was confirmed by the statistical analysis, since the difference in absorbance was statistically significant ( $p$ of $t$-test was $<0.05$ ).

\section{Colony morphology}

The result showed that all colonies of $V$. cholerae wild type strain were smooth since this strain did not form any rugose colony (Figure 3 upper panel). However, it was found that $35 \pm 10 \%$ of toxR mutant strain colonies was rugose (Figure 3 lower panel) and $65 \pm 10 \%$ was smooth. The ability of each strain to form rugose colonies was significantly differed by $\chi 2$ test $(p<0.001)$.

\section{Effect of ToxR protein on growth, survival and rugose colony formation of $V$. cholerae associated with Acanthamoeba castellanii}

Rugose colony formation, growth and survival of $2.0 \pm x$ $10^{6} \mathrm{cell} / \mathrm{mL} V$. cholerae wild type and toxR mutant cultivated in ATCC medium were compared with those of the same strains cultivated with $2.0 \times 10^{5} \mathrm{cell} / \mathrm{mL} A$. castellanii in the same medium.

The result showed that the $V$. cholerae wild type and the toxR mutant survived differently at different temperatures. At $37^{\circ} \mathrm{C}$ the wild type strain grew to $1.3 \times 10^{7}$ $\pm 5.8 \times 10^{6} \mathrm{CFU} / \mathrm{mL}$ and survived 1 day in the absence of amoebae compared to $1.4 \times 10^{2} \pm 5.5 \times 10 \mathrm{CFU} / \mathrm{mL}$ and survived 3 days in the presence of the amoebae, whereas the toxR mutant strain died on the first day in the absence of amoebae but survived 1 day to $4.7 \times 10^{5}$ $\pm 4.0 \times 10^{5} \mathrm{CFU} / \mathrm{mL}$ in the presence of amoebae (Figure 4 upper panel).

At $25^{\circ} \mathrm{C}$ the wild type strain grew to $7.5 \times 10^{7} \pm 1.9 \times$ $10^{7} \mathrm{CFU} / \mathrm{mL}$ and survived 3 days, in the absence of amoebae compared to the tox $R$ mutant strain, which decreased to $2.0 \times 10^{4} \pm 1.0 \times 10^{4} \mathrm{CFU} / \mathrm{mL}$ and survived 2 days. Whereas in the presence of the amoebae, the wild type and the mutant strains grew to $3.3 \times 10^{7}$ $\pm 2.6 \times 10^{7} \mathrm{CFU} / \mathrm{mL}$ and $6.0 \times 10^{7} \pm 3.0 \times 10^{7} \mathrm{CFU} / \mathrm{mL}$ and survived 10 days, respectively (Figure 4 lower panel).

During the cultivation with the amoebae it was observed that the wild type and the toxR mutant strains did not form any rugose colonies at both $25^{\circ} \mathrm{C}$ and $37^{\circ} \mathrm{C}$.

\section{Discussion}

$V$. cholerae adopts several survival strategies in aquatic environments. The bacterium can survive as free-living or in association with zooplankton and can build biofilm and rugose colonies [2,3]. Recent studies have shown that $V$. cholerae has an enhanced growth in association with the free-living amoeba $A$. castellanii at $30^{\circ} \mathrm{C}$ [6-10] 


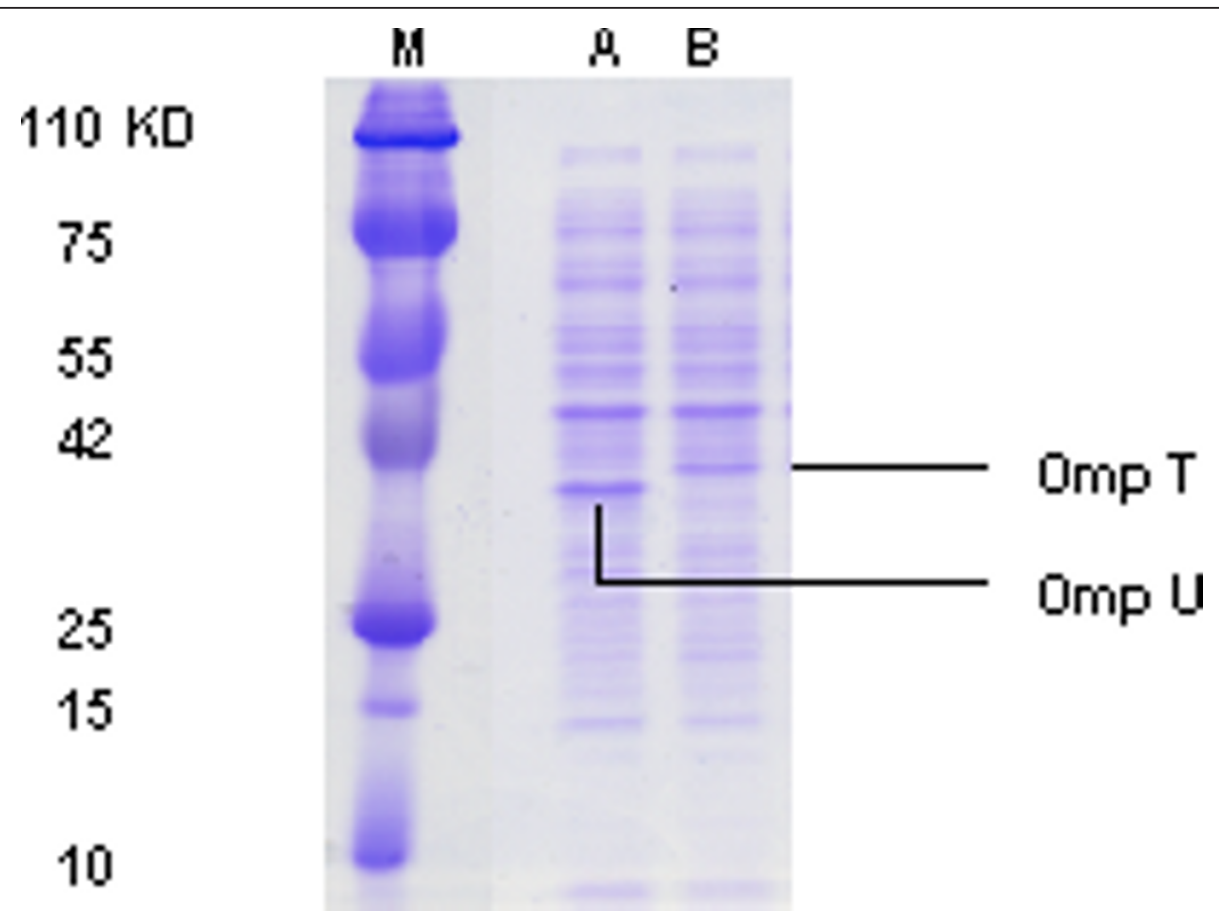

Figure 1 Outer membrane proteins expression by SDS-PAGE gel from whole cell lysates. Lanes $M, A$ and $B$ represent marker, $V$. cholerae wild and toxR mutant strain. The gel confirmed that the wild $V$. cholerae expressed OmpU as it is usually activated by ToxR (A) while the constructed toxR mutant expressed OmpT (B).

and both these microorganisms are detected in same water samples from cholera endemic area [17].

In this study, the internal in-frame toxR deletion mutant V. cholerae strain succeeds to express the ToxRrepressed OmpT instead of the ToxR-activated OmpU. This altered expression of the ToxR-regulated OmpU and OmpT was confirmed by previous study and might affect the viruelence of $V$. cholerae [11].

Our paper has disclosed the role of ToxR regulatory protein in the environmental survival strategies of $V$. cholerae such as biofilm formation, switching from smooth to rugose colony morphotypes and association with the free-living amoeba namely $A$. castellanii.

Our results demonstrate that ToxR clearly affects biofilm and rugose formation since the differences in biofilm and rugose colony formation between $V$. cholerae wild type and toxR mutant were significantly high by $t$ test and $\chi 2$ test, respectively.

Effect of ToxR on growth and survival of $V$. cholerae associated with $A$. castellanii was studied by viable count performed on blood agar. $V$. cholerae wild type strain survived longer than the tox $R$ mutant strain at $37^{\circ} \mathrm{C}$, in the presence or absence of the amoebae. Interestingly, the association with $A$. castellanii enhanced survival of both bacterial strain but the wild type strain survived longer uncovering a role of ToxR in the survival of $V$. cholerae associated with protozoa in aquatic environment.
In cultivation with the amoebae at $25^{\circ} \mathrm{C}$, it was observed that both $V$. cholerae wild type and toxR mutant strains survived more than 10 days.

Despite $V$. cholerae wild type and toxR mutant strains survived more than 10 days in cultivation with the amoebae at $25^{\circ} \mathrm{C}$, these strains did not form any rugose colony indicating that the bacteria avoided starvation. However, presence of the amoebae might enrich the cultivation medium and viable count of the bacteria was performed on enriched plates (blood agar plates).

Analogies to rugosity can be found in a number of other bacterial species, including the expression of alginate by mucoid strains of Pseudomonas aeruginosa and the expression of an adhesive EPS by members of the marine genus [5].

Spontaneous and reversible variation in cell-associated and cell-free EPS production represents an optimal adaptive mechanism that facilitates survival in stressful environments [18].

Although, over 20 genes are co-ordinately controlled by the ToxR regulon [19], the mechanism of switching is currently under study and it seemed to be regulated by exopolysaccharide related phase variation. Phase variation can occur via DNA inversion, DNA recombination, and slipped strand mispairing and is known to be involved in controlling the expression of several surface structures of gramnegative bacteria, including fimbriae, flagella, outer 

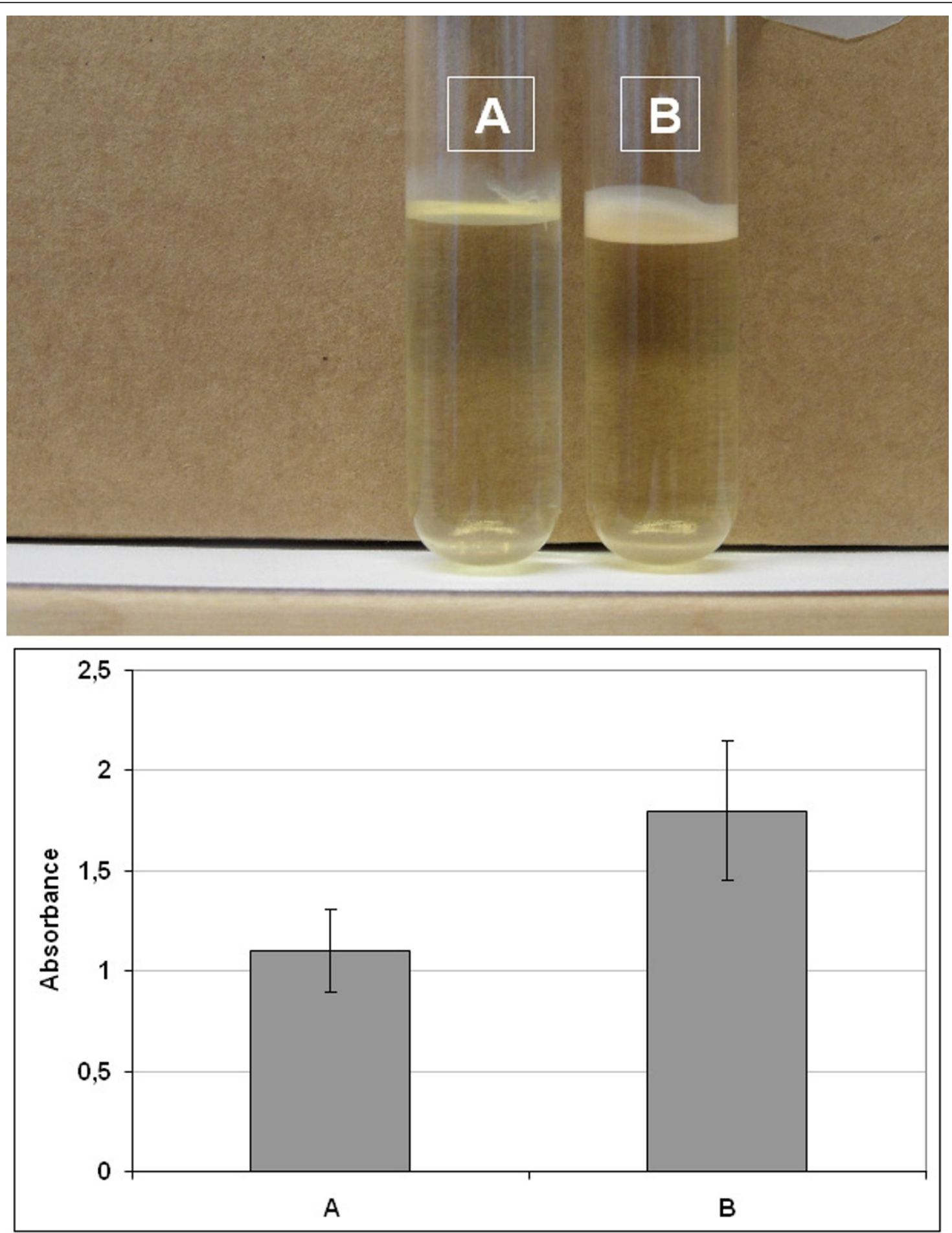

Figure 2 Biofilm formation. Upper panel showed representative photographs of biofilms formed by wild type $V$. cholerae (A) and toxR mutant strain (B). Lower panel showed representative measurement of the absorbance, which is directly proportional to the concentration of biofilmassociated crystal violet formed by wild type $V$. cholerae (A) and toxR mutant (B) strains. Data indicates mean \pm SD of three independent experiments. 


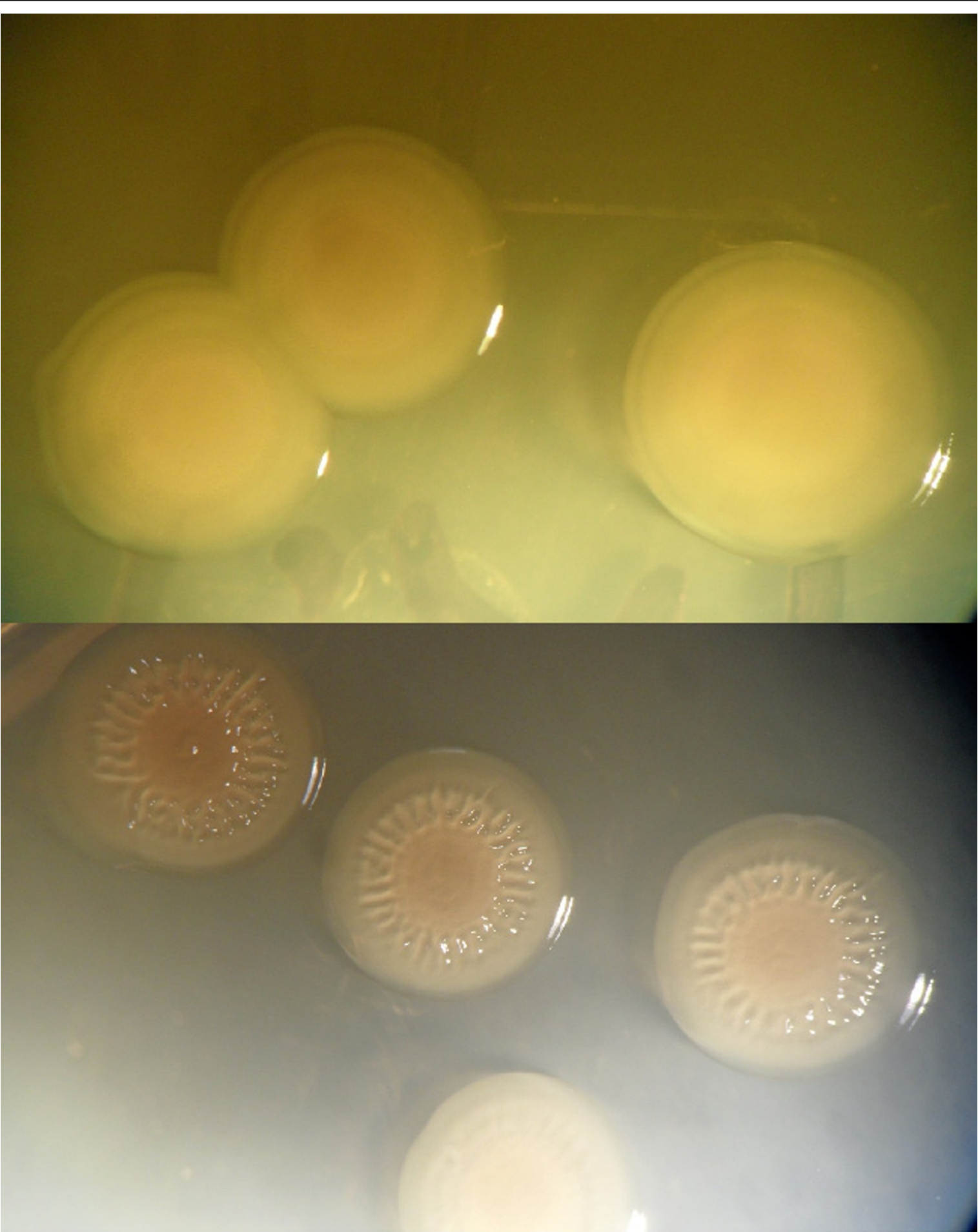

Figure 3 Colony morphology of $\boldsymbol{V}$. cholerae strains. Upper panel represents smooth colonies of wild type strain. Lower panel represents rugose colonies of toxR mutant strain.

membrane proteins, lipopolysaccharide, and capsular polysaccharide [20]. However, role of ToxR was found to be critical for $V$. cholerae bile resistance, virulence factor expression, and intestinal colonization [11,12]. Surprisingly,
ToxR homolog from $V$. anguillarum was found to regulate its own production, bile resistance, and biofilm formation [21] which might emphasis the regulatory role of ToxR in the expression of virulence factors for Vibrio species. 

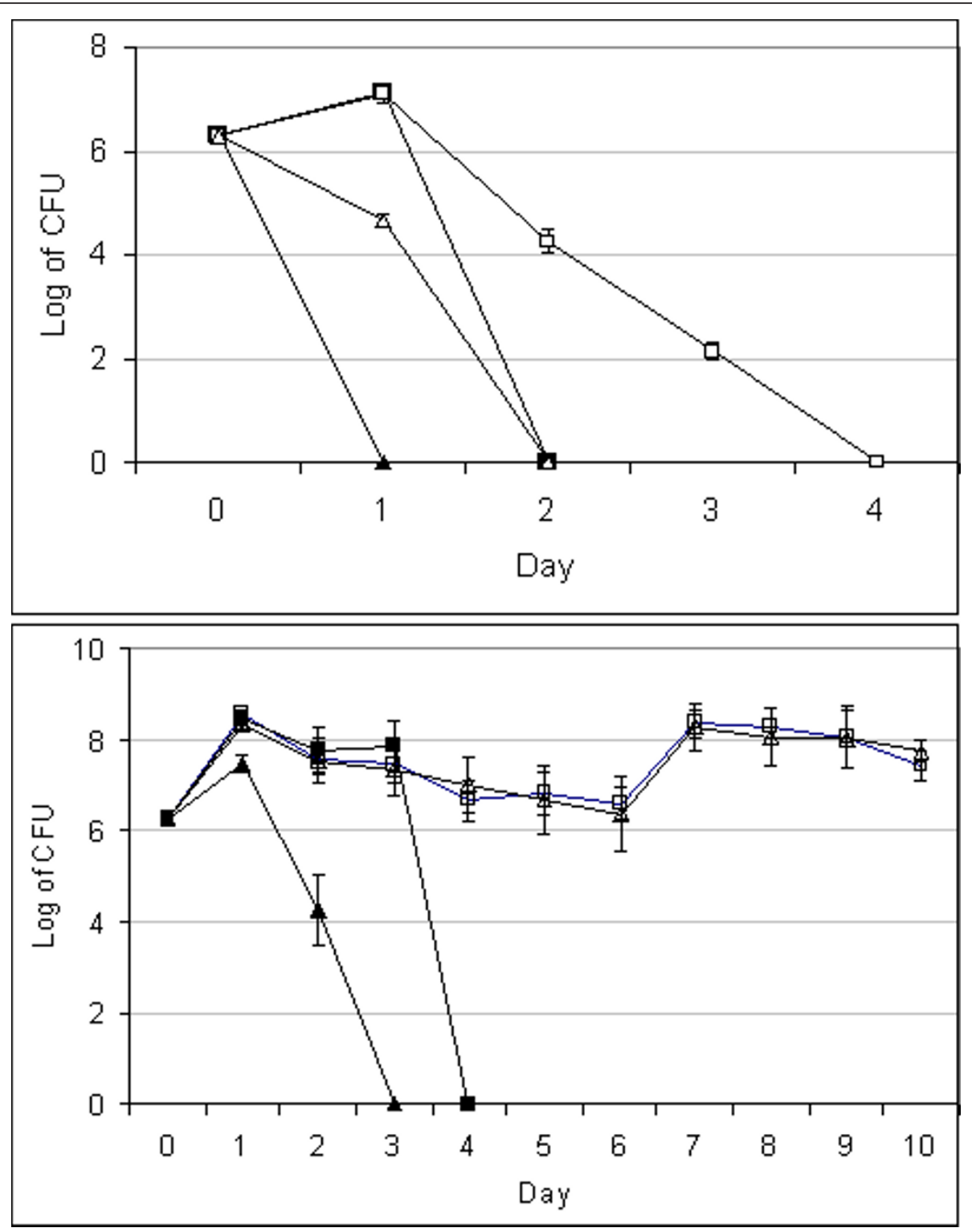

Figure 4 Growth and survival of $V$. cholerae strains in absence and presence of $A$. castellanii at $37^{\circ} \mathrm{C}$ upper panel and at $25^{\circ} \mathrm{C}$ lower panel. Alone cultivated wild type $V$. choleare $(\mathbf{-})$ and cultivated with A. castellanii ( $\square$ ). Alone cultivated toxR mutant strain ( $\mathbf{\Delta})$ and cultivated with A. castellanii $(\triangle)$. Data indicates mean \pm SD of three independent experiments.

\section{Conclusions}

Our results demonstrate that ToxR does seem to play some regulatory role in the OmpT/OmpU expression shift and in the environmental survival strategies of $V$. cholerae such as biofilm formation, switching from smooth to rugose colony and association with the freeliving amoeba $A$. castellanii, suggesting a new role for this regulatory protein.

\section{Acknowledgements}

This project was supported by the Swedish Civil Contingencies Agency (MSB), Project No. 800/2008.

\section{Author details}

'Karolinska Institute, Department of Laboratory Medicine, Division of Clinical Microbiology, Karolinska University Hospital, Huddinge, SE-141 86, Stockholm, Sweden. ${ }^{2}$ Department of Molecular Biology, Umeå University, 90187 Umeå, Sweden.

\section{Authors' contributions}

SV carried out the construction of deletion, outer membrane detection, the analysis of biofilm-and co-cultivation assay and drafted the manuscript. SW contributed to providing of bacterial strains, guiding and design of deletion, and critical reading. AS participated in writing. GS participated in writing and critical reading. HA conceived the study, designed co-infection assay, performed the statistical analysis and helped to draft the manuscript. All authors read and approved the final manuscript. 


\section{Competing interests}

The authors declare that they have no competing interests.

Received: 17 August 2011 Accepted: 16 January 2012

Published: 16 January 2012

\section{References}

1. Tauxe RV, Mintz ED, Quick RE: Epidemic cholera in the new world: translating field epidemiology into new prevention strategies. Emerg Infect Dis 1995, 1(4):141-146.

2. Wai SN, Mizunoe Y, Takade A, Kawabata SI, Yoshida SI: Vibrio cholerae 01 strain TSI-4 produces the exopolysaccharide materials that determine colony morphology, stress resistance, and biofilm formation. Appl Environ Microbiol 1998, 64(10):3648-3655.

3. Islam MS, Jahid MI, Rahman MM, Rahman MZ, Kabir MS, Sack DA, Schoolnik GK: Biofilm acts as a microenvironment for planktonassociated Vibrio cholerae in the aquatic environment of Bangladesh. Microbiol Immunol 2007, 51(4):369-379.

4. Johnson LR: Microcolony and biofilm formation as a survival strategy for bacteria. J Theor Biol 2008, 251(1):24-34.

5. Wrangstadh $\mathrm{M}$, Conway PL, Kjelleberg S: The production and release of an extracellular polysaccharide during starvation of a marine Pseudomonas sp. and the effect thereof on adhesion. Arch Microbiol 1986, 145(3):220-227.

6. Abd H, Saeed A, Weintraub A, Nair GB, Sandstrom G: Vibrio cholerae 01 strains are facultative intracellular bacteria, able to survive and multiply symbiotically inside the aquatic free-living amoeba Acanthamoeba castellanii. FEMS Microbiol Ecol 2007, 60(1):33-39.

7. Abd H, Saeed A, Weintraub A, Sandstrom G: Vibrio cholerae 0139 requires neither capsule nor LPS $\mathrm{O}$ side chain to grow inside Acanthamoeba castellanii. J Med Microbiol 2009, 58(Pt 1):125-131.

8. Abd H, Weintraub A, Sandstrom G: Intracellular survival and replication of Vibrio cholerae 0139 in aquatic free-living amoebae. Environ Microbiol 2005, 7(7):1003-1008.

9. Amir Saeed AH, Edvinsson B, Sandstrom G: Vibrio cholerae-Acanthamoeba castellanii interaction showing endosymbiont-host relation. Symbiosis 2007, 44:153-158.

10. Sandstrom G, Saeed A, Abd H: Acanthamoeba polyphaga is a possible host for Vibrio cholerae in aquatic environments. Exp Parasitol 2010, 126(1):65-68.

11. Provenzano D, Klose KE: Altered expression of the ToxR-regulated porins $\mathrm{OmpU}$ and OmpT diminishes Vibrio cholerae bile resistance, virulence factor expression, and intestinal colonization. Proc Natl Acad Sci USA 2000, 97(18):10220-10224.

12. Provenzano D, Schuhmacher DA, Barker JL, Klose KE: The virulence regulatory protein ToxR mediates enhanced bile resistance in Vibrio cholerae and other pathogenic Vibrio species. Infect Immun 2000, 68(3):1491-1497.

13. Yildiz FH, Schoolnik GK: V. cholerae $01 \mathrm{E} 1$ Tor: identification of a gene cluster required for the rugose col type Exopolysaccharide production chlorine resistance and biofilm formation. Proc Natl Acad Sci USA 1999, 96(7):4028-4033.

14. Yanisch-Perron C, Vieira J, Messing J: Improved M13 phage cloning vectors and host strains: nucleotide sequencing of the $M 13 \mathrm{mp} 18$ and pUC9 vectors. Gene 1985, 33(1):103-119.

15. Donnenberg MS, Kaper JB: Construction of an eae deletion mutant of enteropathogenic Escherichia coli by using a positive-selection suicide vector. Infect Immun 1991, 59(12):4310-4317.

16. Miller VL, Mekalanos JJ: A novel suicide vector and its use in construction of insertion mutations: osmoregulation of outer membrane proteins and virulence determinants in Vibrio cholerae requires toxR. J Bacteriol 1988, 170(6):2575-2583.

17. Shanan S, Abd H, Hedenstrom I, Saeed A, Sandstrom G: Detection of Vibrio cholerae and Acanthamoeba species from same natural water samples collected from different cholera endemic areas in Sudan. BMC Res Notes 2011, 4:109.

18. Link AJ, Phillips D, Church GM: Methods for generating precise deletions and insertions in the genome of wild-type Escherichia coli: application to open reading frame characterization. J Bacteriol 1997, 179(20):6228-6237.
19. Li CC, Merrell DS, Camilli A, Kaper JB: ToxR interferes with CRP-dependent transcriptional activation of ompT in Vibrio cholerae. Mol Microbiol 2002, 43(6):1577-1589.

20. Krinos CM, Coyne MJ, Weinacht KG, Tzianabos AO, Kasper DL, Comstock LE: Extensive surface diversity of a commensal microorganism by multiple DNA inversions. Nature 2001, 414(6863):555-558.

21. Wang SY, Lauritz J, Jass J, Milton DL: A ToxR Homolog from Vibrio anguillaru Serotype $\mathrm{O} 1$ regulates its own production, bile resistance, and biofilm formation. J Bacteriol 2002, 184(6):1630-1639.

doi:10.1186/1756-0500-5-33

Cite this article as: Valeru et al:: ToxR of Vibrio cholerae affects biofilm, rugosity and survival with Acanthamoeba castellanii. BMC Research Notes 2012 5:33.

\section{Submit your next manuscript to BioMed Central and take full advantage of:}

- Convenient online submission

- Thorough peer review

- No space constraints or color figure charges

- Immediate publication on acceptance

- Inclusion in PubMed, CAS, Scopus and Google Scholar

- Research which is freely available for redistribution 